\title{
Light-enhanced oxygen respiration in benthic phototrophic communities
}

\author{
Eric H. G. Epping ${ }^{1, *}$, Bo Barker Jørgensen ${ }^{2}$ \\ ${ }^{1}$ Netherlands Institute for Sea Research, NIOZ, PO Box 59, 1790 AB Den Burg, Texel, The Netherlands \\ ${ }^{2}$ Max Planck Institute for Marine Microbiology, Fahrenheitstr. 1, D-28359 Bremen, Germany
}

\begin{abstract}
Two microelectrode studies demonstrate the effect of light intensity and photosynthesis on areal oxygen respiration in a hypersaline mat at Guerrero Negro, Mexico, and in an intertidal sediment at Texel, The Netherlands. The hypersaline mat was studied in the laboratory at light intensities of 0 , $10,25,50,100,200$, and $500 \mu \mathrm{E} \mathrm{m}^{-2} \mathrm{~s}^{-1}$ using the light-dark shift technique to measure gross photosynthesis rates. Areal gross photosynthesis increased from 0 to $31.3 \mathrm{nmol} \mathrm{O} \mathrm{cm}^{-2} \mathrm{~min}^{-1}$ and areal net photosynthesis increased from -3.9 to $16.7 \mathrm{nmol} \mathrm{O} \mathrm{cm}^{-2} \mathrm{~min}^{-1}$ with increasing light intensities. Areal respiration, calculated from the difference between areal gross and areal net photosynthesis, increased from 3.9 to $14.4 \mathrm{nmol} \mathrm{O}_{2} \mathrm{~cm}^{-2} \mathrm{~min}^{-1}$ with increasing surface irradiance. This light-enhanced areal respiration was related to an increase in oxygen penetration depth from 0.2 to $2.0 \mathrm{~mm}$, thus expanding the volume of sediment involved in oxygen respiration beneath the mat surface. The mean rate of oxygen respiration per volume of mat remained constant at a rate of $\sim 100 \mathrm{nmol} \mathrm{O} \mathrm{cm}^{-3} \mathrm{~min}^{-1}$. Oxygen profiles for the intertidal sediment were recorded in situ during the day at prevailıng lught intensities. A 1-dimensional diffusion-reaction model was used to estimate gross photosynthesis and oxygen respiration per volume of sediment, as well as the euphotic depth and the sediment-water interface concentration of oxygen. Areal gross photosynthesis ranged from 9.7 to $26.3 \mathrm{nmol} \mathrm{O}_{2} \mathrm{~cm}^{-2} \mathrm{~min}^{-1}$ and areal net photosynthesis ranged from 1.1 to $8.1 \mathrm{nmol} \mathrm{O} \mathrm{Cm}^{-2} \mathrm{mın}^{-1}$, both showing maximum values in the early afternoon. Areal respration ranged from 8.1 to $18.2 \mathrm{nmol} \mathrm{O} \mathrm{cm}^{-2} \mathrm{~min}^{-1}$ and showed a good positive linear correlation with areal gross photosynthesis $(R=0.97, n=9)$. The enhanced areal respiration in the intertıdal sediment was due to an increase in mean respiration per volume of sediment from 18.5 to $52 \mathrm{nmol} \mathrm{O}_{2} \mathrm{~cm}^{-3} \mathrm{~min}^{-1}$. The oxygen penetration depth only varied between 3.5 and $4.3 \mathrm{~mm}$. Both studies thus indicate that areal respiration is enhanced significantly with increasing light intensities due to increased areal gross photosynthesis. By assuming that areal respiration in darkness is equal to areal respiration in the light, bell jar incubations would have underestimated areal respiration in the light 3.7-fold and areal gross photosynthesis 1.5 -fold for the hypersaline mat and 10.7 -and 2.6 -fold for the intertidal sediment.
\end{abstract}

KEY WORDS: Microbial mat Microelectrode Photosynthesis Respiration Bell jar

\section{INTRODUCTION}

Benthic phototrophic communities, inhabiting the upper few millimeters of the sediment, may contribute significantly to areal primary production in shallow water environments (e.g. Grøntved 1960, Leach 1970, Marshall et al. 1971, Cadée \& Hegeman 1974, Joint 1978, Revsbech et al. 1981, Colijn \& Jonge 1984, Fielding et al. 1988). The oxygen exchange method and ${ }^{14} \mathrm{C}$-bicarbonate fixation technique are the most

\footnotetext{
•E-mail: eric@postgate.mpi-mm.um-bremen.de
}

commonly used to quantify benthic primary production. The ${ }^{14} \mathrm{C}$-bicarbonate fixation is regarded as the preferred method since it takes into account both oxygenic and anoxygenic photosynthesis as well as chemolithotrophy. The application of this method is limited, however, by the necessity for accurate determinations of the specific activity of the labeled bicarbonate in the thin, productive layer (Revsbech et al. 1981). For sediments in which oxygenic photosynthesis dominates carbon fixation, oxygen evolution can be used to estimate benthic primary production. The sediment oxygen exchange method or bell jar tech- 
nique (Pomeroy 1959) is a simple technique which is still frequently applied in both field and laboratory studies (e.g. Pomeroy 1959, Pamatmat 1968, Hargrave 1969, Gallagher \& Daibu 1974, Hargrave et al. 1983, Nowicky \& Nixon 1985, Murray \& Wetzel 1987, Rizzo et al. 1992). In this technique, an undisturbed area of sediment and a known volume of overlying water are enclosed by a transparent bell jar. The sedimentwater exchange rate of oxygen per unit area of sediment can be calculated from the change in oxygen concentration of the well mixed, enclosed water Exposing the incubated sediment to light thus yields an estimation of areal net photosynthesis, whereas dark incubation provides an estimation of areal dark respiration (Fig. 1). Areal gross photosynthesis is defined as the total of oxygen production by the phototrophic community, i.e. the sum of areal net photosynthesis and areal respiration at identical light conditions. By assuming that areal sediment respiration in dark and light are equal, areal gross photosynthesis is calculated as the sum of areal net photosynthesis and areal dark respiration. In an early comparative study it was shown that the oxygen exchange method exceeded the ${ }^{14} \mathrm{C}$-bicarbonate technique by a factor of 2 to 4 at low light intensities, whereas at high light intensities the ${ }^{14} \mathrm{C}$-bicarbonate technique exceeded the oxygen exchange method by up to a factor of 2.5 . The evolution of gas bubbles was a source of error which may result in the underestimation of benthic

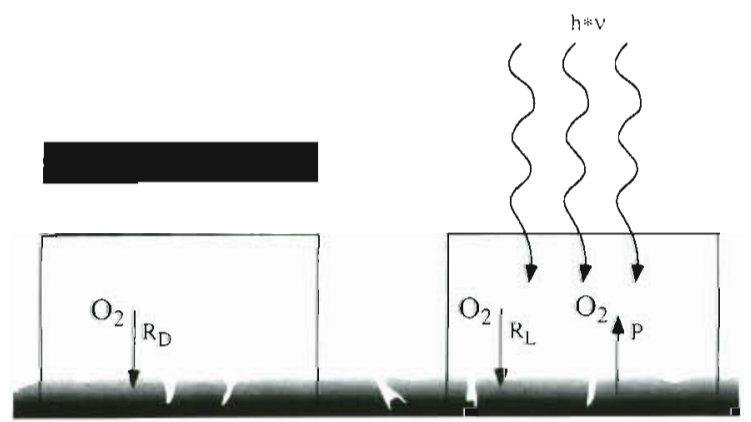

$$
\begin{array}{lr}
\text { Dark: }\left(d O_{2} / d t\right)_{D}=-R_{D} & \text { Light: }\left(d O_{2} / d t\right)_{L}=-R_{L}+P \\
\text { if: } R_{D}=R_{L} ? & \text { or: } P=\left(d O_{2} / d t\right)_{L}+R_{L} \\
& \text { then }\left(d O_{2} / d t\right)_{L}=\left(d O_{2} / d t\right)_{D}
\end{array}
$$

Fig. 1. Schematic representation of the oxygen exchange method or bell jar technique. Areal respiration is estimated from the decrease in oxygen concentration $\left(d \mathrm{O}_{2} / d t\right)_{D}$ of the overlying water during dark incubation (left panel). Areal net photosynthesis is estimated from the change in oxygen concentration $\left(d \mathrm{O}_{2} / d t\right)_{L}$ during light incubation (right panel). Areal gross photosynthesis is calculated by assuming identi$c a l$ rates for areal respiration during dark and light periods. $R_{D}$ is the respiration during the dark period, $R_{L}$ is respiration during the light period, $P$ is gross photosynthesis and h 'v represents light. See text for further explanation primary production by the oxygen exchange method during intensive photosynthesis (Hunding \& Hargrave 1973).

After the introduction of oxygen microelectrode techniques, a new 'light-dark shift method' was described to estimate benthic photosynthesis from oxygen measurements at high vertical resolution in the photic layer of the sediment (Revsbech et al. 1981). A comparison of the oxygen exchange method, the ${ }^{14} \mathrm{C}$-bicarbonate fixation technique and this microelectrode technique showed similar rates for benthic photosynthesis in an oxidised sediment at light intensities $\leq 200 \mu \mathrm{E} \mathrm{m} \mathrm{m}^{-2} \mathrm{~s}^{-1}$. At light intensities of $700 \mu \mathrm{E}$ $\mathrm{m}^{-2} \mathrm{~s}^{-1}$, both the microelectrode technique and the oxygen exchange method underestimated photosynthesis, probably due to interference of gas bubbles. The comparison for a second sediment, which was reduced to the sediment-water interface during the night and oxic down to $2-4 \mathrm{~mm}$ during the day as a result of oxygenic photosynthesis, showed that the oxygen exchange method underestimated primary production in these sediments. It was suggested that oxygen respiration was enhanced due to an increased oxygen penetration during illumination (Revsbech et al. 1981). Hofman et al. (1991) showed that areal respiration increased with increasing rates of areal gross photosynthesis. The enhanced respiration was attributed to oxygen transport into deeper sediment layers during photosynthesis, resulting in an increased biomass of respiring organisms and the oxidation of reduced components in these layers. Lindeboom et al. (1985) showed that gross photosynthesis during light periods in an estuarine sediment enhanced downward fluxes of oxygen by a factor of 1.8 , relative to downward fluxes during dark periods. By assuming identical rates of areal respiration during dark and light periods, areal respiration and gross photosynthesis at noon would be underestimated by a factor of 1.8 and 1.3, respectively.

The aim of this study was to analyse areal respiration with changing light conditions and to evaluate the assumption that areal respiration in benthic phototrophic communities during light and dark periods is equal. Two oxygen microelectrode studies are presented. A cyanobacterial microbial mat was studied at different light intensities in the laboratory, and an intertidal sediment was studied in situ at prevailing light conditions. Areal rates of gross and net photosynthesis and of respiration were calculated from data obtained by the light-dark shift technique (Revsbech \& Jørgensen 1983), or were calculated from the estimated rates of respiration and gross photosynthesis by using a diffusion-reaction model to describe steady state oxygen microprofiles (E.H.G. Epping \& K. Buis unpubl.). 


\section{MATERIALS AND METHODS}

\section{Laboratory measurements: Guerrero Negro, Mexico}

Sampling and mat description. Cyanobacterial mat was collected in April 1985, from an artificial hypersaline pond (Pond 5) situated at Guerrero Negro on the Pacific coast of Baja California, Mexico. The mat had a texture and species composition similar to that previously described for Pond 5 (e.g. D'Antoni D'Amelio et al. 1989, Jorgensen \& Des Marais 1990) or for the 'deep flat mat' from Solar Lake, Sinai (Jørgensen et al. 1983, D'Antoni D'Amelio et al. 1989). Benthic diatoms grew on the mat surface, with the genera Nitzchia and Navicula being most abundant. This community was mixed with coccoid cyanobacteria Synechococcus sp. The dominant mat-building species was the filamentous cyanobacterium Microcoleus chthonoplastes. The organism was present from about $50 \mu \mathrm{m}$ depth and throughout the photic zone, with highest abundancy between 300 and $700 \mu \mathrm{m}$ below the surface. The filamentous cyanobacterium Phormidium sp. was found scattered throughout the photic zone

Intact mat cores were collected by hand in Plexiglas tubes. At the time of sampling the salinity was $86 \%$ and the water temperature was $21^{\circ} \mathrm{C}$. The cores were taken to the laboratory and submerged in water from Pond 5 at near in situ temperature. Aeration and stirring of the water phase was achieved by an airstream, blowing over the water surface. The mat surface was illuminated vertically from above by a $150 \mathrm{~W}$ fiber-optic halogen lamp. Different light intensities on the mat surface were obtained without a change in light quality by varying the distance between the light source and the mat. Light intensities were measured by replacing the core by a LiCor VIS irradiance sensor.

Oxygen measurements. The steady state distribution of oxygen and of photosynthetic activity at light intensities of $0,10,25,50100,200$ and $500 \mu \mathrm{E} \mathrm{m}^{-2} \mathrm{~s}^{-1}$ were determined by use of oxygen microelectrodes. The electrode was mounted to a micromanipulator, secured to a stable iron frame. To prevent shading effects the sensor was positioned at a $30^{\circ}$ angle relative to the light, and measurements were taken at vertical increments of $100 \mu \mathrm{m}$. The applied electrode had a tip diameter of $6 \mu \mathrm{m}$ and a stirring sensitivity of $<1 \%$. The electrode output was measured on a picoampere meter (Keithly 480) connected to a strip chart recorder (Linear 142). The 90\% response time for the complete experimental set-up was about $0.2 \mathrm{~s}$. Calibration of the electrode was done between the oxygen concentration of the overlying water, as determined by Winkler titration, and zero oxygen as encountered deep in the mat.

\section{Field measurements: Texel, The Netherlands}

Site description. Cyanobacterial mats were studied in the intertidal zone of the Frisian Island, Texel. The sediment, consisting of silty sand, was flooded for at least 3 h during every tidal cycle with a mean maximum water depth of about $10 \mathrm{~cm}$. Every fall and winter, the cyanobacterial mat is covered by dune sand, resulting in alternating layers of reduced, black, organic-rich sediment and white, low-organic sediment. The surface of the mat is inhabited by pennate diatoms, whereas Microcoleus chthonoplastes is the dominant filamentous cyanobacterium. During the day of measurement in August 1992, the water temperature ranged from 15 to $18^{\circ} \mathrm{C}$ and the salinity was $23 \%$.

Oxygen measurements. The diurnal variation in the vertical distribution of oxygen was determined in situ by the use of commercially available Clark type microelectrodes (Diamond Electrotech, \#737). The applied electrodes had tip diameters of $60 \mu \mathrm{m}$ and a stirring sensitivity of 1 or $2 \%$. A computerized micromanipulator was designed for field measurements. Five electrodes were mounted to a transparent cylinder filled with Fluorinert solution (FC77, 3M Alkmaar, The Netherlands) to reduce electrical noise. The electrodes were moved vertically along a rail by a $12 \mathrm{~V}$ motor, and positioned horizontally by a 2-dimensional manual micro-positioning frame. Profiles were recorded with a vertical resolution of $50 \mu \mathrm{m}$ and with an intermittent stabilisation period of 3 s between successive readings. Vertical position and electrode outputs were stored in a Tattletale solid state memory (Model 5, $128 \times 8$ RAM, 3B Engineering, Rotterdam, The Netherlands). Calibration of the electrodes was done between the oxygen concentration of the overlying water as determined by Winkler titration and anoxia prevailing deep down in the mat

Calculations. For the cyanobacterial mat, the depth distribution of gross photosynthesis at different light intensities was determined by the light-dark shift technique (Revsbech \& Jørgensen 1983). Gross photosynthesis was calculated from the decrease in oxygen during a brief shading period. Depending on the photosynthetic rate a shading period of 2 to $4 \mathrm{~s}$ was applied. The measured rate is a porewater activity which is multiplied with sediment porosity, $\phi$, to obtain the activity per volume of wet sediment, $P_{(\text {vol })}$. The sediment porosity for the cyanobacterial mat is assumed to be depth independent and equal to 0.9

Areal gross photosynthesis, gross $P_{(a r e a)}$, was calculated by integration of gross photosynthesis rates from the sediment-water interface down through the euphotic zone, according to

$$
\text { gross } P_{\text {lared } j}=\sum_{z=0}^{z=Z_{\text {phot }}} P_{(\text {vot })}
$$


where $z$ is depth in the sediment and $Z_{p h o}$ is the depth of the euphotic zone, i.e. the maximum depth for which gross photosynthesis can be detected. Mean volumetric gross photosynthesis, $\bar{P}_{\{\text {vol },}$ was calculated from the gross $P_{(a r e a)}$ divided by the depth of the euphotic zone:

$$
\bar{P}_{(v o l)}=\frac{\text { gross } P_{(a r e a)}}{Z_{\text {phot }}}
$$

Net areal photosynthesis is equal to the flux of oxygen across the sediment-water interface, and is positive if the flux is directed to the overlying water. It was calculated from the steady state oxygen microprofile by applying Fick's first law of diffusion

$$
\text { net } P_{\text {(area) }}=\left.\phi D_{s} \frac{d C}{d z}\right|_{z=0}
$$

where $\left.\frac{d C}{d z}\right|_{z=0}$ and $D$ s denote the oxygen concentration gradient at the sediment-water interface and the whole sediment diffusion coefficient, respectively. The steepest oxygen gradient just below the interface was used to calculate net areal photosynthesis. The whole sediment molecular diffusion coefficient was assumed to be $90 \%$ of the free solution coefficient corrected for temperature (Li \& Gregory 1974). Because of the extreme environment of the mat, e.g. high salinity and sulfide concentration, the contribution of faunal activity to transport is probably not significant, which resulted in a whole sediment diffusion coefficient of $1.91 \times 10^{-5} \mathrm{~cm}^{-2} \mathrm{~s}^{-1}$. Diffusivity $\left(\phi D_{s}\right)$ thus corresponds to $1.72 \times 10^{-5} \mathrm{~cm}^{-2} \mathrm{~s}^{-1}$, which is somewhat higher then the experimentally determined diffusivity for a temperate cyanobacterial mat (Glud et al. 1995)

Areal respiration, $R_{\text {(area) }}$ was calculated from the difference between areal gross and areal net photosynthesis:

$$
R_{\text {(area })}=\operatorname{gross} P_{\text {(area })}-\text { net } P_{(a r e d)}
$$

The mean respiration per volume of sediment, $\bar{R}_{\text {ivol } \mid r}$ was calculated from the ratio of areal respiration, and the maximum oxygen penetration depth, $Z_{\text {max }}$ :

$$
\bar{R}_{(\text {wol })}=\frac{\bar{R}_{\text {(area) }}}{Z_{\text {max }}}
$$

For the intertidal sediment, in situ oxygen profiles were analysed using a 2-layered, 1-dimensional diffusion-reaction model, developed by Epping \& Buis (unpubl.). The model allows the estimation of mean gross photosynthesis per volume of porewater, $\bar{P}$, the mean oxygen respiration per volume of porewater, $\bar{R}$, the sediment-water interface concentration of oxygen, $C_{0}$ and the maximum depth of gross photosynthesis, $Z_{\text {phot }}$. These parameters can be estimated by minimising the sum of squares between the experimental pro- file and the theoretical curve, calculated from the combination of 2 polynomials.

For depth zero to $\mathcal{Z}_{\text {phoil }}$ :

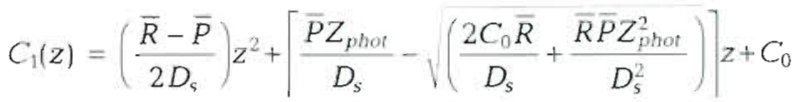

For depth $Z_{\text {phot }}$ to the maximum oxygen penetration depth, $Z_{\text {max: }}$ :

$C_{2}(z)=\left(\frac{\bar{R}}{2 D_{s}}\right) z^{2}-\left[V\left(\frac{2 C_{0} \bar{R}}{D_{s}}+\frac{\bar{R} \bar{P} Z_{\text {phot }}^{2}}{D_{s}^{2}}\right)\right] z+\frac{\bar{P} Z_{\text {phot }}^{2}}{2 D_{s}}+C_{0}$

Depth, $z_{1}$ is zero at the sediment-water interface and positive into the sediment.

Multiplying the estimated pore water activities of mean volumetric gross photosynthesis and mean volumetric respiration with porosity will give mean volumetric activities per volume of wet sediment, $\bar{P}_{\text {(vol) }}$ and $\bar{R}_{(\text {voll) }}$ comparable to Eqs. (2) \& (5), respectively.

Areal gross photosynthesis for the intertidal sediment was calculated as:

$$
\text { gross } P_{\text {(areat }}=\bar{P}_{(\text {vol })} \times \mathcal{Z}_{\text {phot }}
$$

and areal respiration was calculated as:

$$
R_{\text {(area) }}=\tilde{R}_{\text {(vol) }} \times Z_{\max }
$$

Areal net photosynthesis was calculated from Eq. (3), where $\left.\frac{d C}{d z}\right|_{z=0}$ is the first derivative of Eq. (6) at zero depth

The average porosity for the top $5 \mathrm{~mm}$ of the sediment was estimated as 0.89 from the gravimetric change after drying known volumes of sediment overnight at $105^{\circ} \mathrm{C}$. The whole sediment diffusion coefficient for the intertidal sediment was calculated from the free solution diffusion coefficient for oxygen, $D_{0}$, corrected for temperature (Li \& Gregory 1974) and corrected for tortuosity (Andrews \& Bennett 1.981):

$$
D_{\mathrm{s}}=\frac{D_{0}}{\phi F(0)}
$$

where $F(0)$ denotes the resistivity formation factor at the sediment-water interface. The resistivity formation factor was calculated from:

$$
F(z)=\frac{R_{s}(z)}{R_{w}}
$$

where $R_{s}(z)$ and $R_{w}$ denote the resistivity of the sedi-

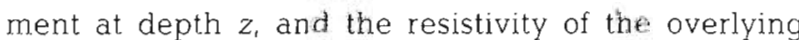
water, respectively (Andrews \& Bennett 1981). Resistivity was recorded with a vertical resolution of $1 \mathrm{~mm}$ using a 4 -wire resistivity probe. The formation factor at 
the sediment-water interface was estimated as 1.3. Consequently, the effective transport coefficient for the intertidal sediment corresponded to $89 \%$ of the free solution molecular diffusion coefficient.

\section{RESULTS}

\section{Light-dark-shift experiments, cyanobacterial mat}

The steady state oxygen profiles at different incident photon fluxes are shown in Fig. 2. The effective diffusive boundary layer, defined as the extrapolation of the linear concentration gradient at the sediment-water interface to the bulk water concentration (Boudreau \& Guinasso 1982, Andrews \& Hargrave 1984, Jørgensen \& Revsbech 1985, Jørgensen \& Des Marais 1990), was ca $200 \mu \mathrm{m}$ thick for all profiles. The sediment oxygen maximum increased to $1100 \mu \mathrm{M}$ or about 1.4 atm partial pressure of $\mathrm{O}_{2}$ with increasing surface irradiance.

Fig. $3 \mathrm{~A}-\mathrm{F}$ depicts the vertical distribution of gross photosynthesis with increasing surface light intensities. Photosynthesis reached a maximum value, which was constant for the surface layer extending from 0.0 to $0.4 \mathrm{~mm}$, when light intensities increased from 10 to $100 \mu \mathrm{E} \mathrm{m}^{-2} \mathrm{~s}^{-1}$. No increase in photosynthesis was observed in this layer at even higher light intensities. The relative contribution of the 0.0 to $0.4 \mathrm{~mm}$ surface layer to areal gross photosynthesis decreased from $83 \%$ at $10 \mu \mathrm{E} \mathrm{m} \mathrm{m}^{-2} \mathrm{~s}^{-1}$ to $13 \%$ at $500 \mu \mathrm{E} \mathrm{m}^{-2} \mathrm{~s}^{-1}$. High rates of photosynthesis, reaching maximum values at a light intensity of $500 \mu \mathrm{E} \mathrm{m}^{-2} \mathrm{~s}^{-1}$, were observed in the

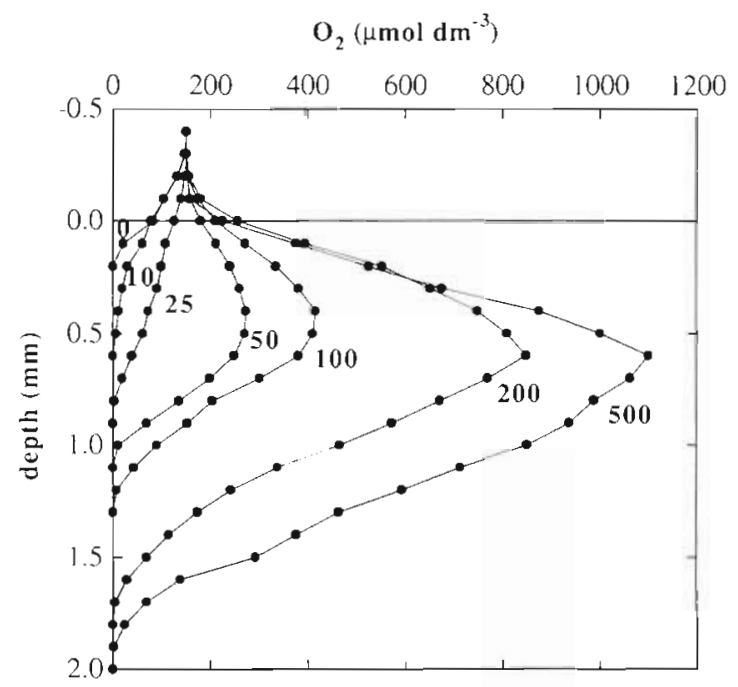

Fig. 2. Steady state oxygen profiles in a cyanobacterial mat from Guerrero Negro, Mexico. Profiles were recorded in the laboratory, April 1985, at light intensities as indicated on the curves $\left(\mu E \mathrm{~m}^{-2} s^{-1}\right)$. Temperature and salinuty of the overlying water were $21^{\circ} \mathrm{C}$ and $86 \%$, respectively
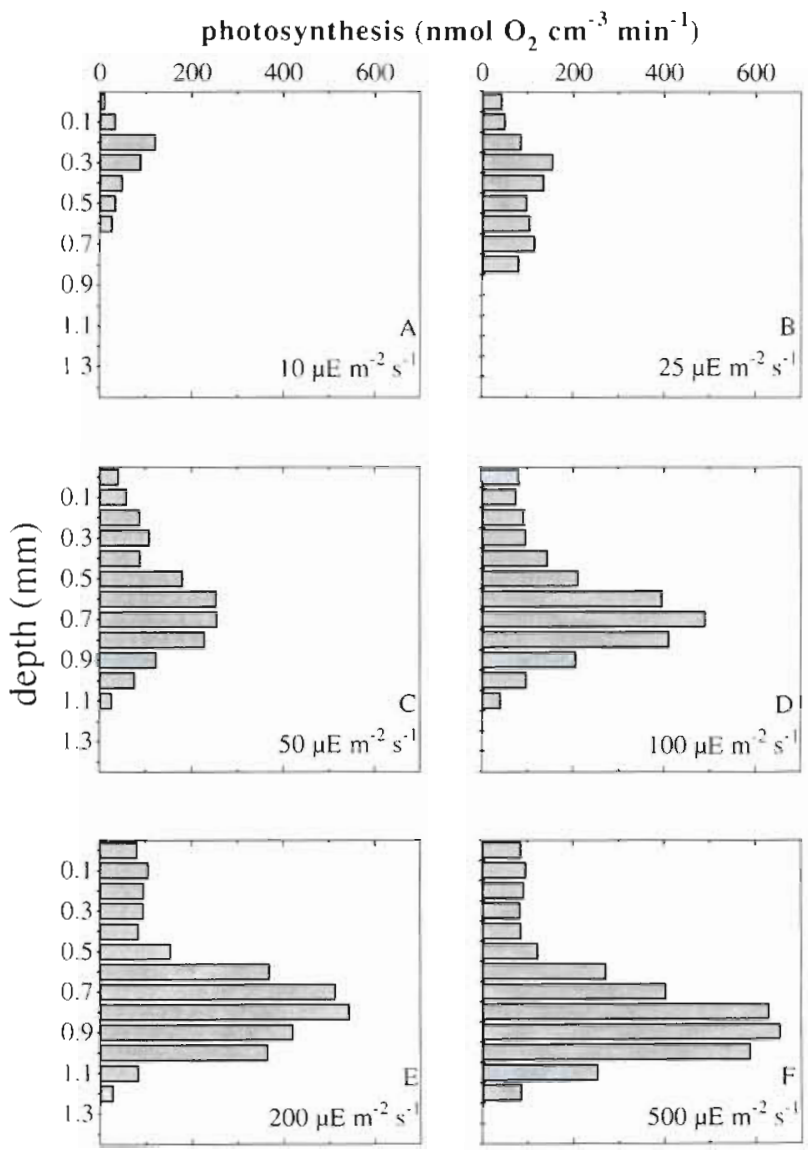

Fig. 3. Depth distributions of gross photosynthesis in a cyanobacterial mat from Guerrero Negro at 6 different light intensities $\left(\mu \mathrm{E} \mathrm{m}^{-2} \mathrm{~s}^{-1}\right)$

layer extending from $0.5 \mathrm{~mm}$ down to $1.2 \mathrm{~mm}$. From these photosynthesis profiles, $P$-I curves (photosynthesis vs light intensity) have been constructed for $0.0,0.5$, 0.8 and $1.1 \mathrm{~mm}$ depth (Fig. 4A-D). These P-I curves for selected depths should be regarded as 'apparent $P$-I curves' since irradiance is scaled to incident light intensity at the mat surface, rather than to light intensity at the indicated depth. For the depths $0.0,0.5$, and $0.8 \mathrm{~mm}$, gross photosynthesis showed light saturation. At $1.1 \mathrm{~mm}$ depth, photosynthesis increased linearly

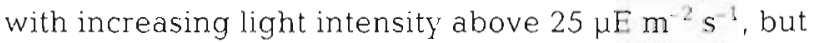
did not reach saturation at $500 \mu \mathrm{E} \mathrm{m} \mathrm{m}^{-2} \mathrm{~s}^{-1}$ No gross photosynthesis was recorded at light intensities of 10

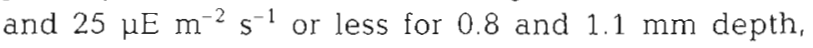
respectively. The maximum rates of photosynthesis

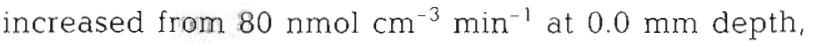
$180 \mathrm{nmol} \mathrm{cm} \mathrm{cmin}^{-1}$ at $0.5 \mathrm{~mm}$ depth, to $630 \mathrm{nmol} \mathrm{cm}^{-3}$ $\mathrm{min}^{-1}$ at $0.8 \mathrm{~mm}$ depth.

From the $\mathrm{O}_{2}$ profiles in Fig. 2, areal net photosynthesis was calculated as the flux of oxygen across the sediment-water interface. The resulting rates were $-3.9 \mathrm{nmol} \mathrm{cm}^{-2} \mathrm{~min}^{-1}$ in darkness and showed satura- 


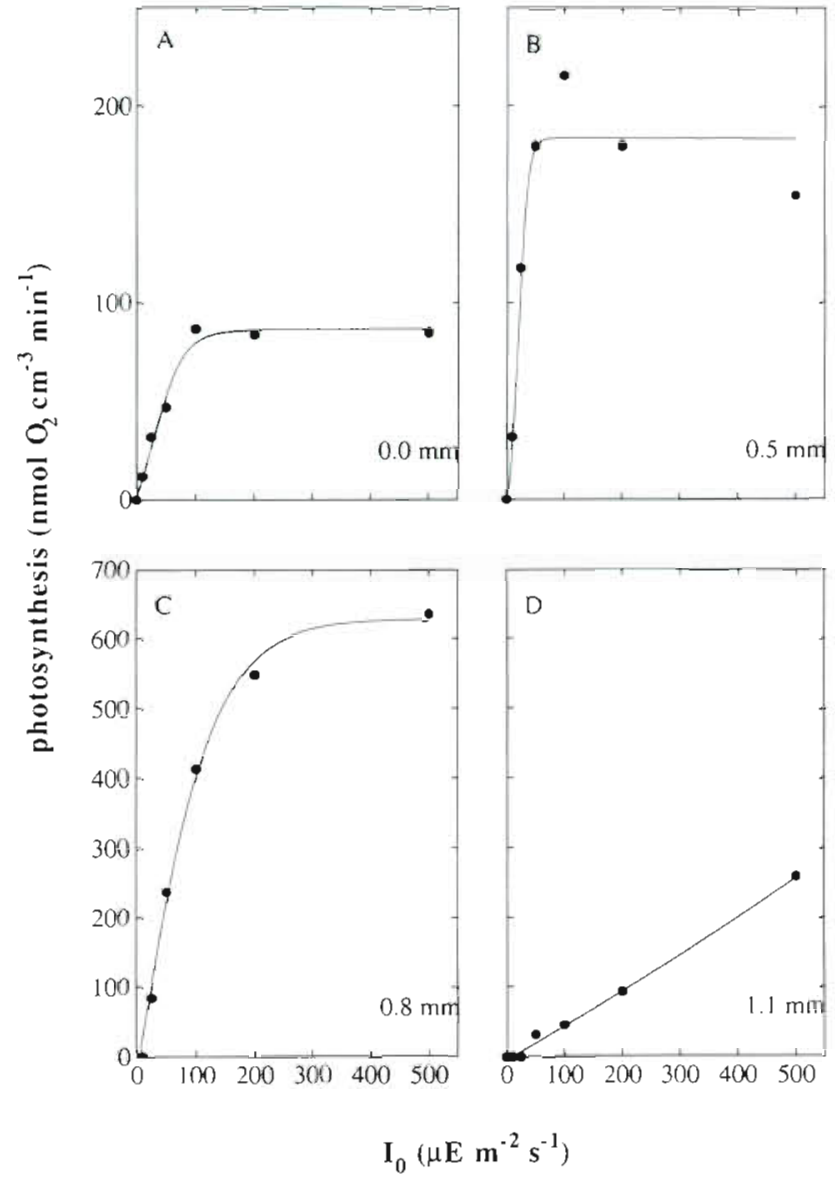

Fig. 4. Gross photosynthesis at 4 different depths plotted against incident surface light intensity, based on data from Fig. 3

tion at $16.7 \mathrm{nmol} \mathrm{cm}^{-2} \mathrm{~min}^{-1}$ with increasing light intensity up to $500 \mu \mathrm{E} \mathrm{m}^{-2} \mathrm{~s}^{-1}$ (Fig. 5A). The light intensity at oxygen compensation, where net photosynthesis equals zero, was $30 \mu \mathrm{E} \mathrm{m}^{-2} \mathrm{~s}^{-1}$ The oxygen concentration profiles showed a 10 -fold increase in the thickness of the oxic zone, $Z_{\max }$ from $0.2 \mathrm{~mm}$ in the dark to $2 \mathrm{~mm}$ at maximum irradiance (Fig. 5B).

Areal gross photosynthesis increased with increasing light intensity from $3.32 \mathrm{nmol} \mathrm{cm} \mathrm{mm}^{-2} \mathrm{~min}^{-1}$ at $10 \mu \mathrm{E}$

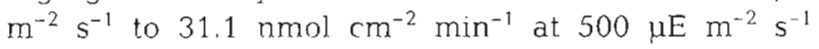
(Fig. 5C). The thickness of the euphotic zone, $Z_{\text {phot }}$ increased from $0.7 \mathrm{~mm}$ at $10 \mu \mathrm{E} \mathrm{m} \mathrm{m}^{-2} \mathrm{~s}^{-1}$ to $1.3 \mathrm{~mm}$ at 200 to $500 \mu \mathrm{E} \mathrm{m}^{-2} \mathrm{~s}^{-1}$. The mean volumetric gross photosynthesis increased from 0 to $240 \mathrm{nmol} \mathrm{cm} \mathrm{m} \mathrm{min}^{-1}$ over the imposed range of illuminations (Fig. 5D).

Areal respiration, $R_{\text {(areay }}$ showed saturation with increasing incident light intensity. In the dark, it was

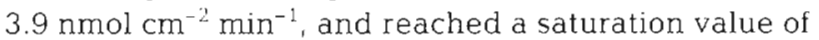
$14.4 \mathrm{nmol} \mathrm{cm}{ }^{-2} \mathrm{~min}^{-1}$ at 200 to $500 \mu \mathrm{E} \mathrm{m}^{-2} \mathrm{~s}^{-1}$ (Fig. 5E). Mean sediment volumetric respiration, $\bar{R}_{\{\text {vol } \mid}$, was approximately $100 \mathrm{nmol} \mathrm{cm}^{-3} \mathrm{~min}^{-1}$ and probably independent of light intensity (Fig. 5F).
Areal respiration, $R_{\text {(area })}$ increased linearly with areal gross photosynthesis, gross $P_{\text {lareaj }}$ (Fig. 6A). Over the entire range of surface irradiances, on average $35 \%$ of the areal gross photosynthesis was respired within the sediment. $Z_{\max }$ showed a linear increase with increasing $R_{\text {larea) }}$ (Fig. 6B), which indicates that the enhanced $P_{\text {(area) }}$ with increasing incident light intensity was the result of an expansion of the oxic zone.

The oxygen concentration profiles from Fig 2 were used in a 1-dimensional diffusion-reaction model to compare rates as estimated from the concentration profile with rates calculated from the light-dark shift technique. Moreover, it was examined whether the 2 ways of quantitative analysis yield similar relationships between different parameters.

The model estimates for, gross $P_{\text {(area) }}$ net $P_{\text {(area) }}$ and $R_{\text {(area) }}$ are plotted against the data calculated from the light-dark shift technique in Fig. $7 \mathrm{~A}-\mathrm{C}$. The model cal-
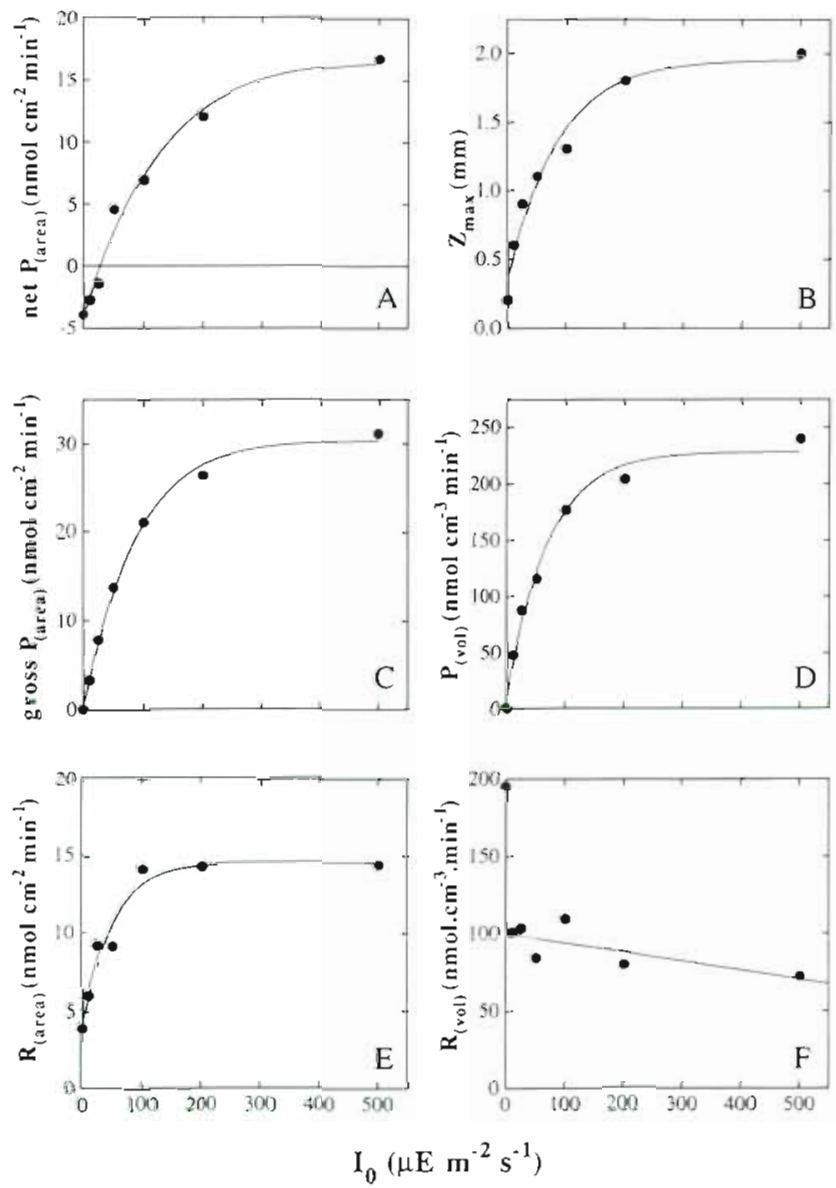

Fig. 5. (A) Areal net photosynthesis, net $P_{\text {lareal }}$ (B) maximum oxygen penetration depth, $Z_{\max }(C)$ areal gross photosynthesis, gross $P_{\text {lareaj; }}$ (D) mean volumetric gross photosynthesis, $\bar{P}_{\text {ivaij; }}(\mathrm{E})$ areal respiration, $R_{\text {idreaji }}$ and (F) mean volumetric res-

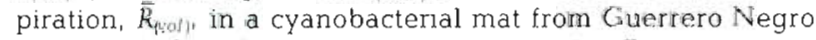
plotted against the incident photon flux 


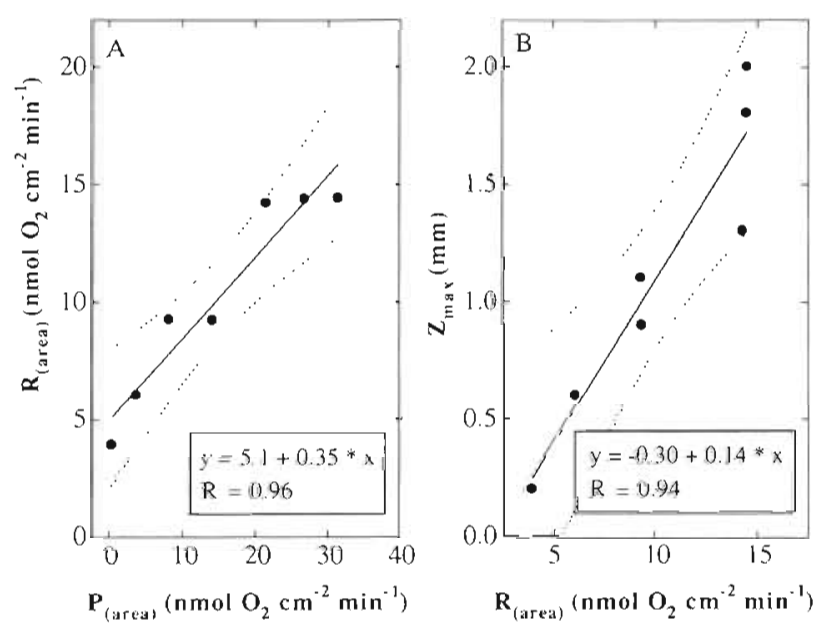

Fig. 6. (A) Areal respiration, $R_{\text {lareal, }}$ as a function of areal gross photosynthesis, gross $P_{\text {(area; }}$ and (B) relationship between the maximum oxygen penetration depth, $Z_{\max }$ and, $R_{\text {(aredi, }}$ for the cyanobacterial mat at Guerrero Negro. Dotted lines indicate $95 \%$ confidence interval of the regression line

culation showed an excellent correlation with the light-dark shift technique ( $R=0.89$ to 0.99 ). The model parameters, $\bar{P}_{\text {ivol })}, \bar{R}_{\text {(vol })}$, and $Z_{\text {phol }}$ and the derived quantities, $Z_{\text {max }}$ gross $P_{(\text {area })}$, net $P_{\text {(area) }}$, and $R_{\text {(area), were }}$ compared with the corresponding parameters calculated from the light-dark shift method (Table 1). Compared with the light-dark shift technique, the model overestimated the areal rates by 47 to $93 \%$ and the mean volumetric gross photosynthesis by $121 \%$, whereas the depth of the photic zone was underestimated by the model by ca $30 \%$.

In accordance with the light-dark shift analysis, the model analysis shows that $R_{\text {iareal }}$ increases proportional to $Z_{\text {max }}$ with increasing light intensities.

\section{Field measurements, intertidal sediment}

Fig. 8 shows in situ oxygen profiles for the intertidal sediment over a diel light cycle in the absence of clouds. The thickness of the effective diffusive boundary layer varied between 200 and $600 \mu \mathrm{m}$. The sediment oxygen maximum increased from 12:00 till 13:36 h and subsequently declined. A similar trend (data not shown) was observed for the mean volumetric gross photosynthesis, $\bar{P}_{\text {ivoli, }}\left(85.0\right.$ to $264 \mathrm{nmol} \mathrm{cm}^{-3}$ $\left.\min ^{-1}\right)$, mean volumetric respiration, $\bar{R}_{(\text {vol })}$ (20 to $52 \mathrm{nmol} \mathrm{cm}^{-3} \mathrm{~min}^{-1}$ ), areal respiration, $R_{\text {(area), }}(8$ to $18 \mathrm{nmol} \mathrm{cm}^{-2} \mathrm{~min}^{-1}$ ), and areal gross photosynthesis, gross $P_{\text {lareal. }}\left(10\right.$ to $\left.26 \mathrm{nmol} \mathrm{cm} \mathrm{cmin}^{-1}\right)$.

As observed for the cyanobacterial mat, the areal respiration increased linearly with areal gross photosynthesis $(R=0.97$, Fig. 9A). On average, $66 \%$ of the areal gross photosynthesis was respired in the sediment. The oxygen penetration depth as calculated from the model estimates, $Z_{\text {max }}$ did not increase with the calculated areal respiration (Fig. 9B). Conversely, the model estimates for the volumetric oxygen respiration showed a strong positive correlation $(\mathrm{R}=0.99)$ with calculated areal respiration (Fig 9C). These observations suggest that, in contrast with the cyanobacterial mat, enhanced areal respiration was here due to enhanced volumetric respiration, rather than due to an expansion of the oxic zone.

\section{DISCUSSION}

The vertical distribution of photosynthesis and the $P$-I curves for the cyanobacterial mat suggests the presence of at least 2 distinct photosynthetic populations: a surficial population from 0.0 to $0.4 \mathrm{~mm}$ and a
Fig. 7 Comparison of (A) areal gross photosynthesis, gross $P_{(d r e a)}$ : (B) areal net photosynthesis, net $P_{\text {Iareaj; }}$ and (C) areal respiration, $R_{\text {tared }}$ estimated with a 1 -dimensional diffusion-reaction model with data from light-dark shift technique for the cyanobacterial mat at Guerrero Negro. Model estimates were obtained from oxygen profiles in Fig. 2. Solid lines indicate linear regression of the relation between the model and light-dark shift data. Dotted lines indicate $95 \%$ confidence interval of the regression line
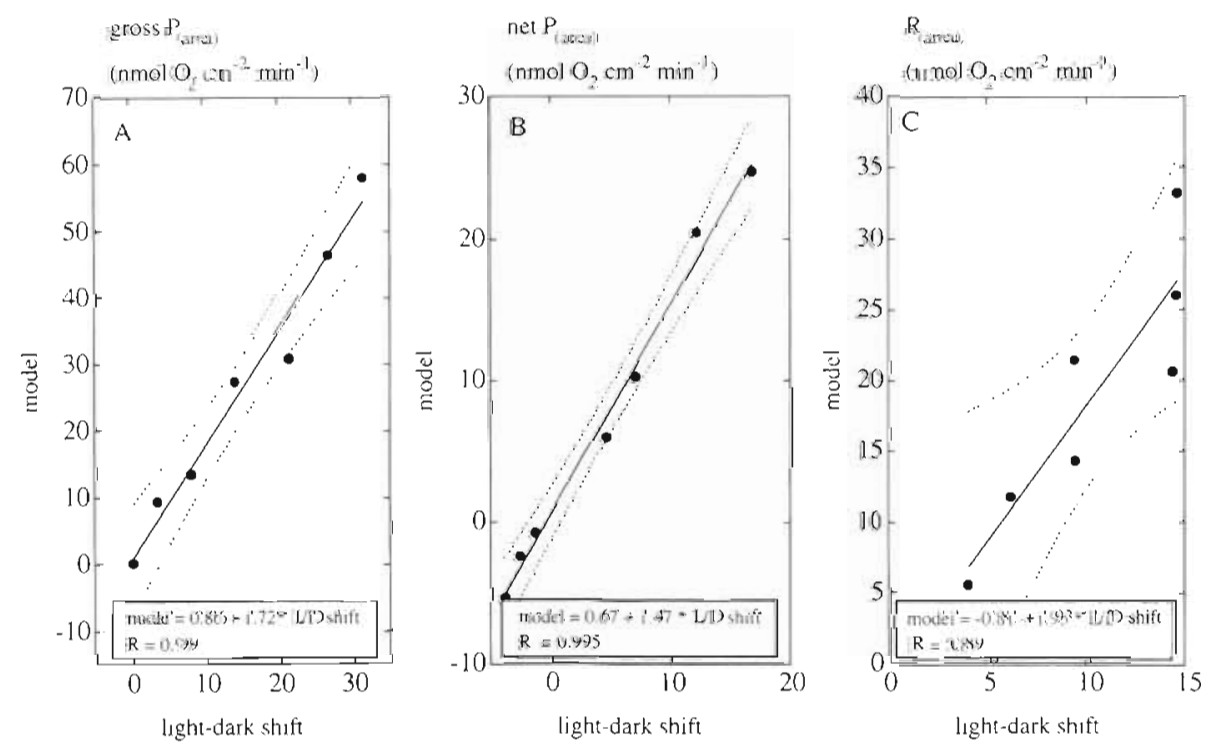
Table 1. Companson of areal net photosynthesis, net $P_{\text {area, }}$ areal gross photosynthesis, gross $P_{\text {lareal, }}$ mean volumetric gross photosynthesis, $\vec{P}_{(v o l)}$, depth of the euphotic zone, $Z_{\text {phow }}$ areal respiration, $R_{\text {area }}$, mean volumetric respiration, $\bar{R}_{(v o l)}$, and maximum oxygen penetration depth, $Z_{\text {max }}$, measured by the light-dark shift technique and estimated by a model from steady state oxygen microprofiles for the cyanobacterial mat, in Mexico in April 1985.

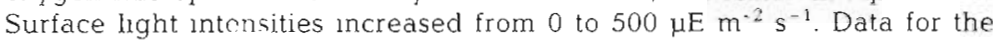
intertidal sediment were obtained from modelling oxygen profiles presented in Fig.8. Profiles for the intertidal sediment were recorded in situ, in The Netherlands in August 1992

\begin{tabular}{|c|c|c|c|c|}
\hline & $\begin{array}{c}\text { Mat, } \\
\text { L-D-shift }\end{array}$ & $\begin{array}{l}\text { Mat, } \\
\text { model }\end{array}$ & $\begin{array}{c}\text { Intertidal, } \\
\text { model }\end{array}$ & Units \\
\hline net $P_{(\text {area })}$ & $-3.9-16.7$ & $=5.5-24.7$ & $1.1-8.1$ & $\mathrm{nmol} \mathrm{O}_{2} \mathrm{~cm}^{-2} \mathrm{~min}^{-1}$ \\
\hline gross $P_{\text {|areat }}$ & $0-31.3$ & $0-57.8$ & $9.7-26.3$ & $\mathrm{nmol} \mathrm{O}_{2} \mathrm{~cm}^{-2} \mathrm{~min}^{-1}$ \\
\hline $\bar{P}_{\text {ivoij }}$ & $0-239.2$ & $0-517$ & $63-263$ & $\mathrm{nmol} \mathrm{O} \mathrm{cm}^{-3} \mathrm{~min}^{-1}$ \\
\hline$Z_{\text {phot }}$ & $0-1.3$ & $0-1.1$ & $0.8-1.9$ & $\mathrm{~mm}$ \\
\hline$R_{\text {(aredi }}$ & $3.9-14.4$ & $5.5-33.1$ & $8.1-18.2$ & $\mathrm{nmol} \mathrm{O} \mathrm{cm}^{-2} \mathrm{~min}^{-1}$ \\
\hline $\bar{R}_{\text {ivol }\}}$ & $72-195$ & $135-191$ & $18.5-52.0$ & $\mathrm{nmol} \mathrm{O} \mathrm{cm}^{-3} \mathrm{~min}^{-1}$ \\
\hline$Z_{\max }$ & $0.2-2.0$ & $0.4-2.0$ & $3.5-4.3$ & $\mathrm{~mm}$ \\
\hline
\end{tabular}

means of phycobilins (Jorgensen et al 1987). Due to scattering and absorption by light harvesting pigments, the light quantity and spectral quality at the very surface differ from the incident light and also change strongly below the mat surface (Jorgensen \& Des Marais 1988, Kühl \& Jørgensen 1992, 1994, Lassen et al. 1992, Ploug et al. 1993). However, for a microbial mat on sandy sediments along the coast of Limfjorden, Denmark, a reduction to $85 \%$ in spectral light quality at the lower boundary of the euphotic zone for diatoms and an increase to $107 \%$ for cyanobacteria were calculated, relative to the quality of incident light. Thus spectral complementarity only partly explained the microzonation of diatoms and cyanobacteria, and total light intensity and chemical gradients were suggested as additional factors (Ploug et al. 1993).

deeper population from 0.5 to $1.2 \mathrm{~mm}$. Photosynthesis in the upper layer was associated with a mixed population of diatoms (Nitzschia and Navicula) and coccoid cyanobacteria (Synechococcus sp.), whereas the deeper activity in photosynthesis was associated with the dominant mat building population of Microcoleus chthonoplastes. For a similar mat it was shown that the diatoms and cyanobacteria have a partly complementary utilisation of the light spectrum. The diatoms at the mat surface utilized blue light and red light, which are absorbed by the chlorophyll $a$ and carotenoids, whereas the cyanobacteria also absorbed the passing intermediate spectrum between 550 and $650 \mathrm{~nm}$ by

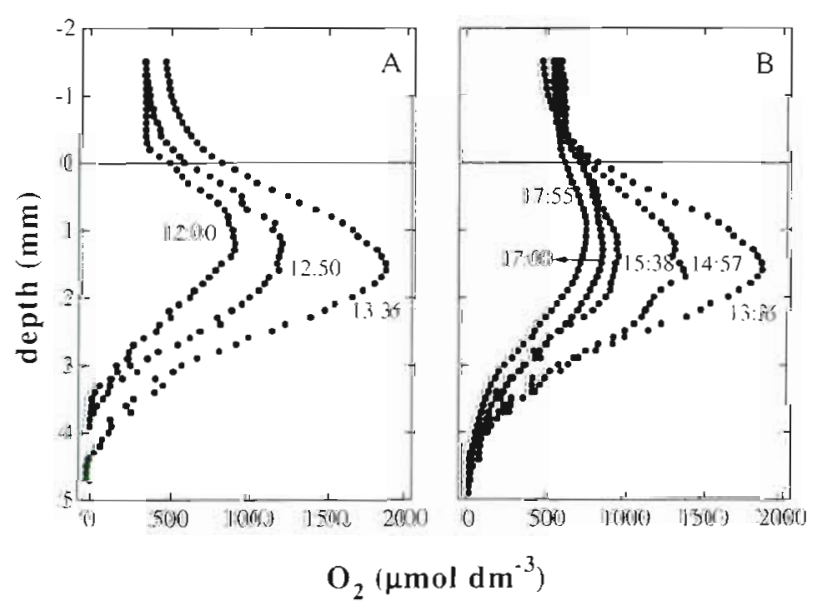

Fig. 8. Mean oxygen profiles ( $\mathrm{n}=3$ to 5 ), measured in situ in an intertidal sediment at Texel. Profiles were recorded at indicated times during a clear sunlit day in August 1992. Temperature and salinity of the overlying water were 15 to $18^{\circ} \mathrm{C}$ and $23 \%$ respectively
For the cyanobacterial mat in Guerrero Negro, hydrogen sulfide might be crucial for the microzonation of diatoms and cyanobacteria. In the upper layer of the mat, the sulfide sensitive diatoms are protected from toxic levels by the presence of oxygen and the sulfide oxidising activity of the colorless sulfur bacteria Beggiatoa spp. The sulfide tolerance (Castenholz 1976, Jørgensen \& Cohen 1977, Howlsley \& Pearson 1979, Wit \& van Gemerden 1989) and the adaptation to low light levels (Pentecost 1984, Whale \& Walsby 1984, GarciaPichel et al. 1994) may explain the high abundance of Microcoleus chthonoplastes deeper in the mat.

Areal gross photosynthesis of the cyanobacterial mat increased with increasing surface irradiance and reached a rate of $31.1 \mathrm{nmol} \mathrm{cm} \mathrm{cmin}^{-1}$ at light saturation (Fig. 5C). This increase in areal gross photosynthesis was due to both increased photosynthesis rates and a deepening of the photic zone. As a consequence, the sediment oxygen concentration as well as the oxygen gradient at the sediment-water interface increased. Below a compensation light intensity of $30 \mu \mathrm{E}$ $\mathrm{m}^{-2} \mathrm{~s}^{-1}$ (Fig. 5A), the flux of oxygen across the interface was directed towards the sediment and net areal photosynthesis was negative. The compensation light intensity marks the change from a net heterotrophic to a net autotrophic community. At higher light intensities, areal gross photosynthesis exceeds areal respiration, the flux of oxygen is directed towards the overlying water, and net photosynthesis increases to positive values. Over the imposed range of light intensities,

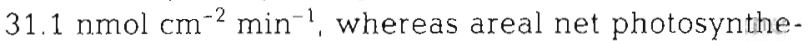
sis only increased from -3.9 to $16.7 \mathrm{nmol} \mathrm{cm} \mathrm{cm}^{-2} \mathrm{~min}^{-1}$. The difference between areal gross and areal net phothe areal gross photosynthesis increased from 0 to 
Fig. 9. (A) Areal respiration, $R_{\text {idred }}$. as a function of areal gross photosynthesis, gross $P_{\text {arear; }}$ (B) maxjmum oxygen penetration depth, $Z_{\text {maxi }}$ against areal respiration; and (C) mean volumetric respiration, $\vec{R}_{(v o l)}$ against areal respiration for the intertidal sediment, at Texel. Data were obtained by modeling the oxygen profiles in Fig. 8. Dotted lines indicate $95 \%$ confidence interval of the regression line
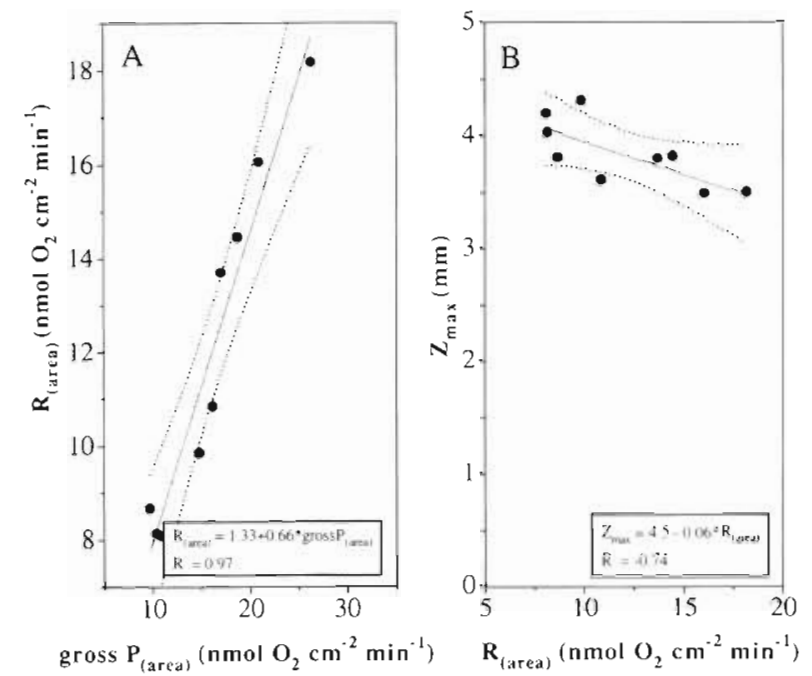

tosynthesis, which is due to respiration, increased with increasing surface irradiance. For the cyanobacterial mat, this light enhanced areal respiration was accompanied by an increased penetration depth of oxygen. The oxygen was thus respired by a larger volume of sediment, i.e. by a larger microbial population, whereas the mean volumetric respiration remained rather constant with increasing light intensities. Therefore, light enhanced areal respiration of the cyanobacterial mat may be attributed to the expansion of the oxic layer. Changes in penetration depth of oxygen with changing light intensities have been reported for both marine and limnic benthic phototrophic communities (e.g. Jørgensen et al. 1979, Epping \& Buis unpubl.), indicating that this is a common effect of changes in areal gross photosynthesis.

For the intertidal sediment, the model calculations showed a concurrent increase in areal respiration with increasing areal gross photosynthesis. In contrast to the cyanobacterial mat it was the volumetric respiration which was enhanced as the areal gross photosynthesis increased, rather than the oxic zone which expanded. Similar observations were made by Lindeboom et al. (1985) for diatom covered sediments. Despite changes in gross photosynthesis over a diel light cycle, only minor changes in the penetration depth of oxygen were recorded by these authors. Calculated downward fluxes of oxygen during the light periods were on average a factor of 1.8 higher than the downward flux during dark periods. Apparently, increased rates of photosynthesis enhanced the volumetric rate of respiration. Since reported saturation constants for oxygen respiration are low compared to the sediment oxygen concentration (e.g. 0.11 to 3.1 $\mu \mathrm{M} \mathrm{O} \mathrm{O}_{2}$; Rabouille \& Gaillard 1991, Gerritse et al. 1992), it is unlikely that respiration in the intertidal sediment was enhanced directly by the increase in oxygen concentration. It is suggested that excessive production and subsequent excretion of photosynthate during high rates of photosynthesis may have stimulated heterotrophic respiratory processes in the intertidal sediment (Haack \& McFeters 1982, Ward et al. 1987)

The areal rates for the cyanobacterial mat as estimated by the model are significantly higher than the corresponding rates calculated from the light-dark shift technique. In the model it is assumed that volumetric gross photosynthesis is independent of depth. Therefore, the application of the model to oxygen profiles from the cyanobacterial mat is questionable, since gross photosynthesis clearly showed a maximum in the subsurface layer at light intensities exceeding $25 \mu \mathrm{E}$ $\mathrm{m}^{-2} \mathrm{~s}^{-1}$. For the intertidal sediment the distribution of photosynthesis with depth is unknown, and we are not able to quantify the overestimation of areal rates. The model-fits to these oxygen profiles, representing the average of 3 to 5 profiles, were better than those for the cyanobacterial mat. Therefore, we expect that the error in estimating areal rates for the intertidal sediment is less than that for the cyanobacterial mat, and that this error will not seriously affect the conclusions drawn from model calculations.

Both studies clearly show that increasing rates of areal gross photosynthesis not only results in enhanced areal net photosynthesis but also in enhanced areal respiration. Increasing rates of gross photosynthesis may expand the volume of oxic sediment or stimulate the volumetric respiration by enhanced photosynthate exudation. For both situations, areal respiration as measured during light incubation is much higher than in the dark. In bell jar measurements, however, areal gross photosynthesis is estimated by summing areal respiration in the dark and areal net photosynthesis in the light. The areal respiration in the light, and there- 
fore also the areal gross photosynthesis, will be underestimated by this approach (cf. Lindeboom et al. 1985, Hofman et al. 1991)

Table 2 shows the estimations for areal gross photosynthesis and for areal respiration by extrapolating dark areal respiration to maximum surface irradiance. For the cyanobacterial mat, gross photosynthesis is underestimated by a factor of 1.5, whereas areal respiration is underestimated by a factor of 3.7 These factors amount to 1.9 and 6, respectively, by making the same assumption for model estimated rates.

For the intertidal sediment no oxygen profiles are available to estimate areal respiration during dark incubation. Calculating areal dark respiration from the lowest estimation of volumetric respiration in the light will presumably still overestimate areal respiration in the dark, since respiration may be generally enhanced during photosynthesis (cf. Lindeboom et al. 1985, Hofman et al. 1991). Following this approach will yield conservative numbers for the underestimation of areal gross photosynthesis and areal respiration. Areal dark respiration, calculated from the lowest estimation for volumetric respiration in the light $\left(18.5 \mathrm{nmol} \mathrm{O}_{2} \mathrm{~cm}^{-3}\right.$ $\mathrm{min}^{-1}$ ) thus results in an underestimation of areal gross photosynthesis and areal respiration by a factor of 2.6 and 8.7 , respectively, at maximum rates of areal gross photosynthesis.

Table 2. Companson of measured areal gross photosynthesis, gross $P_{\text {(area) }}$, at $500 \mu \mathrm{E} \mathrm{m}^{-2} \mathrm{~s}^{-1}$ as calculated from the sum of areal respiration, $R_{\text {torea }}$ in darkness and areal net photosynthesis, net $P_{\text {(areal }}$ at $500 \mu \mathrm{E} \mathrm{m} \mathrm{m}^{-2} \mathrm{~s}^{-1}$ A second comparison is made for $R_{\text {(area) }}$ in darkness with $R_{\text {(areal }}$ at $500 \mu \mathrm{E} \mathrm{m}^{-2} \mathrm{~s}^{-1}$ For the hypersaline mat, both results of the light-dark shift technique and results from modeling the oxygen microprofiles with a diffusion-reaction model are presented. For the intertidal sediment, $R_{\text {(ared }}$ in darkness is calculated by assuming a volumetric respiration of $18.5 \mathrm{nmol} \mathrm{O}_{2} \mathrm{~cm}^{-3} \mathrm{~min}^{-1}$

\begin{tabular}{|c|c|c|c|}
\hline & $\begin{array}{l}\text { Mat, } \\
\text { L/D-shift }\end{array}$ & $\begin{array}{l}\text { Mat, } \\
\text { model }\end{array}$ & $\begin{array}{c}\text { Intertidal, } \\
\text { model }\end{array}$ \\
\hline $\begin{array}{l}R_{\text {tarea }} \text { at } 0 \mu \mathrm{E} \mathrm{m}^{-2} \mathrm{~s}^{-1} \\
\left(\mathrm{nmol} \mathrm{O}_{2} \mathrm{~cm}^{-2} \mathrm{~min}^{-1}\right)\end{array}$ & 3.9 & 5.5 & 2.1 \\
\hline $\begin{array}{l}\text { net } P_{\text {(area) }} \text { at } 500 \mu \mathrm{E} \mathrm{m}^{-2} \mathrm{~s}^{-1} \\
\left(\mathrm{nmol} \mathrm{O} \mathrm{cm}^{-2} \mathrm{~min}^{-1}\right)\end{array}$ & 16.7 & 24.7 & 8.1 \\
\hline $\begin{array}{l}R_{\text {lareal }}+\text { net } P_{\text {|areal }} \\
\left(\text { nmol } \mathrm{O}_{2} \mathrm{~cm}^{-2} \mathrm{~min}^{-1}\right)\end{array}$ & 20.6 & 30.2 & 10.2 \\
\hline $\begin{array}{l}\text { gross } P_{\text {(ared) }} \\
500 \mu \mathrm{Em}^{-2} \mathrm{~s}^{-1}\end{array}$ & 31.3 & 57.8 & 26.3 \\
\hline$\frac{\text { gross } P_{\text {larea) }}}{R_{\text {(areal }}+\text { net } P_{\text {(area) }}}$ & 1.5 & 1.9 & 2.6 \\
\hline $\begin{array}{l}R_{\text {(drea) }} \text { at } 500 \mu \mathrm{E} \mathrm{m}^{-2} \mathrm{~s}^{-1} \\
\text { (nmol } \mathrm{O}_{2} \mathrm{~cm}^{-2} \mathrm{~min}^{-1} \text { ) }\end{array}$ & 14.4 & 33.1 & 18.2 \\
\hline$\frac{R_{\text {(area) }} \text { light }}{R_{\text {(area) }} \text { dark }}$ & 3.7 & 6.0 & 8.7 \\
\hline
\end{tabular}

In conclusion, bell jar incubations may provide accurate estimations of dark areal respiration and of areal net photosynthesis. However, the gross photosynthesis of the benthic phototrophic community and the respiration during light periods are significantly underestimated

Acknowledgements. The organisation by David J. Des Marais of the field research at Guerrero Negro, Mexico, and the technical assistance of Marc Staal are gratefully acknowledged. We thank Kerst Buis for helpful discussions and W. Helder for carefully reading the manuscript. This study was supported by a U.S. National Research Council associateship (B.B.J.) and by grant no. 437.023 from the Foundation for Fundamental Biological Research (BION), which is subsidized by the Netherlands Organization for Advancement of Pure Science (NWO) (E.E.).

\section{LITERATURE CITED}

Andrews D, Bennett A (1981) Measurements of diffusivity near the sediment-water interface with a fine-scale resistivity probe. Geochim Cosmochim Acta 45:2169-2175

Andrews D. Hargrave B'T (1984) Close interval sampling of interstitial silicate and porosity in marine sediments. Geochim Cosmochim Acta 48:711-722

Boudreau BP, Guinasso jr NL (1982) The influence of a diffusive sublayer on accretion, dissolution and diagenesis at the sea floor. In: Fanning KA Yiunheim FT (eds) The dynamic environment of the ocean floor. Lexington Books, p $115-146$

Cadée GC, Hegeman J (1974) Primary production of the benthic microflora living on tidal flats in the Dutch Wadden Sea. Neth J Sea Res 8:260-291

Castenholz RW (1976) The effect of sulfide on the blue green algae of hot springs. J Phycol 12:57-68

Colijn F, de Jonge VN (1984) Primary production of microphytobenthos in the Ems-Dollard estuary. Mar Ecol Prog Ser 14:185-196

D'Antoni D'Amelio E, Cohen Y, Des Marais DJ (1989) Comparative functional ultrastructure of two hypersaline submerged cyanobacterial mats: Guerrero Negro, Baja California Sur, Mexico, and Solar Lake, Sinai, Egypt. In: Cohen Y, Rosenberg E (eds) Microbial mats: physiological ecology of benthic microbial communities. American Society for Microbuology, Washington, DC. p 97-113

Flelding PJ, Damstra K St. J, Branch GM (1988) Benthic diatom biomass, production and sediment chlorophyll in Langebaan Lagoon, South Africa. Estuar Coast Shelf Sci 29:183-194

Gallagher JL, Daibu FC (1974) Primary production of edaphic algal communities in a Delaware salt marsh. Limnol Oceanogr 19(4):390-395

Garcia-Plchel F, Mechling M, Castenholz RW (1994) Diel migrations of microorganisms within a benthic, hypersaline mat community. Appl Environ Microbiol 60:1500-1511

Gerritse J, Schut F, Gottschal JC (1992) Modelling of mixed chemostat cultures of an aerobic bacterium, Comamonas testosteroni, and an anaerobic bacterium. Veillonella alcalescens: comparison with experimental data. Appl Environ Microbiol 58(5):1466-1476

Glud RN, Jensen K, Revsbech NP (1995) Diffusivity in surficial sediments and benthic mats determined by use of a combined $\mathrm{N} 2 \mathrm{O}-\mathrm{O} 2$ microsensor Geochim Cosmochim Acta 59:231-237 
Grontved J (1960) On the productivity of microbenthos and phytoplankton in some Danish fjords. Medd Dan Fisk Havunders 3:1-17

Haack TK, McFeters GA (1982) Nutritional relationships among microorganisms in an epilithic biofilm community. Microb Ecol 8:115-126

Hargrave BT (1969) Epibenthic algal production and community respiration in the sediments of Marion Lake. J Fish Res Bd Can 26:2003-2026

Hargrave BT, Prouse NJ, Phillips GA, Neame PA (1983) Primary production and respiration in pelagic and benthic communities at two intertidal sites in the upper Bay of Fundy. Can J Fish Aquat Sci 40 (Suppl 1):229-243

Hofman PAG, de Jong SA, Wagenvoort EJ, Sandee AJJ (1991) Apparent sediment diffusion coefficients for oxygen and oxygen consumption rates measured with microelectrodes and bell jars: applications to oxygen budgets in estuarine intertidal sediments (Oosterschelde, SW Netherlands). Mar Ecol Prog Ser 69:261-272

Howlsley R, Pearson HW (1979) pH dependent sulfide toxicity to oxygenic photosynthesis in cyanobacteria. FEMS Microbiol Lett 6:287-292

Hunding C, Hargrave BT (1973) A comparison of benthic algal production measured by ${ }^{14} \mathrm{C}$ and oxygen methods. J Fish Res Bd Can 30:309-312

Joint IR (1978) Microbial production of an estuarine mudflat. Estuar Coast Mar Sc1 7:185-195

Jargensen BB, Cohen Y (1977) Solar Lake (Sinai). 5. The sulfur cycle of benthic cyanobacterial mats. Limnol Oceanogr 22:657-666

Jargensen BB, Cohen Y, Des Marais DJ (1987) Photosynthetic action spectra and adaptation to spectral light distribution in a benthic cyanobacterial mat. Appl Environ Microbiol $53(4): 879-886$

Jorgensen BB, Des Marais DJ (1988) Optical properties of benthic photosynthetic communities: fiber-optic studies of cyanobacterial mats. Limnol Oceanogr 33(1):99-113

Jorgensen BB, Des Marais DJ (1990) The diffusive boundary layer of sediments: oxygen microgradients over a microbial mat. Limnol Oceanogr 35(6):1343-1355

Jorgensen BB, Revsbech NP (1985) Diffusive boundary layers and the oxygen uptake of sediments and detritus. Limnol Oceanogr 30(1):111-122

Jorgensen BB, Revsbech NP, Blackburn TH, Cohen Y (1979) Diurnal cycle of oxygen and sulfide microgradients and microbial photosynthesis in a cyanobacterial mat sediment. Appl Environ Microbiol 38:46-58

Jorgensen BB, Revsbech NP, Cohen Y (1983) Photosynthesis and structure of benthic microbial mats: microelectrode and SEM studies of four cyanobacterial communities. Limnol Oceanogr 28:1075-1093

Kühl M, Jørgensen BB (1992) Spectral light measurements in microbenthic phototrophic communities with a fibre-optic microprobe coupled to a sensitive diode array detector. Limnol Oceanogr 37(8):1813-1823

Kuhl M, Jørgensen BB (1994) The light field of microbenthic communities: radiance distribution and microscale optics of sandy coastal sediments. Limnol Oceanogr 39(6): $1368-1398$

Lassen C, Ploug H, Jørgensen BB (1992) Microalgal photosynthesis and spectral scalar irradiance in coastal marine sediments of Limfjorden, Denmark. Limnol Oceanogr $37(4): 760-772$
Leach JH (1970) Epibenthic algal production in an intertidal mudflat. Limnol Oceanogr 15(4):514-521

Li YH, Gregory S (1974) Diffusion of ions in sea water and in deep-sea sediments. Geochim Cosmochim Acta 38: $703-714$

Lindeboom HJ, Sandee AJJ, de Klerk-vd Driessche HAJ (1985) A new bell jar/microelectrode method to measure changing oxygen fluxes in illuminated sediments with a microalgal cover. Limnol Oceanogr 30(3):693-698

Marshall N, Oviatt CA, Skauen DK (1971) Productivity of the benthic microflora of shoal estuarine environments in southern New England. Int Rev Ges Hydrobiol 56:947-956

Murray L, Wetzel RL (1987) Oxygen production and consumption associated with the major autotrophic components in two temperate seagrass communuties. Mar Ecol Prog Ser 38:231-239

Nowicky BL, Nixon SW (1985) Benthic community metabolism in a coastal lagoon ecosystem. Mar Ecol Prog Ser 22: $21-30$

Pamatmat MM (1968) Ecology and metabolism of a benthic community of an intertidal sand-flat. Int Rev Ges Hydrobiol 53:211-298

Pentecost A (1984) Effects of sedimentation and light intensity on mat-forming Oscillatoriaceae with particular reference to Microcoleus lyngbyaceus Gomont. J Gen Microbiol 130 . $983-990$

Ploug H, Lassen C, Jørgensen BB (1993) Action spectra of microalgal photosynthesis and depth distribution of spectral scalar irradiance in a coastal marine sediment of Limfjorden, Denmark. FEMS Microbiol Ecol 102:261-270

Pomeroy LR (1959) Algal productivity in salt marshes of Georgia. Limnol Oceanogr 4:386-397

Rabouille C, Gaillard JF (1991) Towards the EDGE: Early Diagenetic Global Explanation. A model depicting the early diagenesis of organic matter, $\mathrm{O}_{2}, \mathrm{NO}_{3}, \mathrm{Mn}$, and $\mathrm{PO}_{4}$ Geochim Cosmochim Acta 55:2511-2525

Revsbech NP, Jørgensen BB (1983) Photosynthesis of benthic microflora measured with high spatial resolution by the oxygen microprofile method: capabilities and limitations of the method. Limnol Oceanogr 28(4):749-756

Revsbech NP, Jorgensen BB, Brix O (1981) Primary production of microalgae in sediments measured by oxygen microprofile, $\mathrm{H}^{14} \mathrm{CO}_{3}{ }^{-}$fixation, and oxygen exchange methods. Limnol Oceanogr 26(4):717-730

Rizzo WM, Lackey GJ, Christian RR (1992) Signifcance of euphotic, subtidal sediments to oxygen and nutrient cycling in a temperature estuary. Mar Ecol Prog Ser 86: $51-61$

Ward DM, Tayne TA, Anderson KL, Bateson MM (1987) Community structure and interactions among community members in hot spring cyanobacterial mats. In: Fletcher M, Gray TRS, Jones JG (eds) Ecology of microbial communities. Cambridge University Press, Cambridge, p $179-210$

Whale GF, Walsby AE (1984) Motility of the cyanobacterium Microcoleus chthonoplastes in mud. Br Phycol J 19: $117-123$

Wit $R$ de, van Gemerden $H$ (1989) Growth responses of the cyanobacterium Microcoleus chthonoplastes with sulfade as an electron donor. In: Cohen $Y$, Rosenberg $E$ (eds) Microbial mats: physiological ecology of benthic micropbial communities. American Society for Microbiology Washington, DC, p 320-325

Manuscript first received: July 19, 1995

Revised version accepted: January 9, 1996 